\title{
Entrepreneurship Education Based on Experiential Teaching Reform
}

\author{
Jianan Wang ${ }^{\mathrm{a}}$, Liansheng Yang ${ }^{\mathrm{b},{ }^{*}}$ \\ Dalian University of Technology, Liaoning Province, Dalian City, 116024, China. \\ a13998791118@163.com, , b84707554@163.com
}

Keywords: College entrepreneurship education; experiential teaching; application.

\begin{abstract}
Entrepreneurship education is not only the education of enterprises to create skills, but also a new concept and model of education. It is a quality education aiming at cultivating innovative and entrepreneurial talents. It includes education of entrepreneurship and quality, education of entrepreneurship and three levels of entrepreneurship skills education content. Experiential teaching can not only enable students to meet the requirements of students' knowledge development, but more importantly, it also aims at the cultivation of students' abilities, including innovation ability, teamwork ability, organization ability, communication and coordination ability, and summarizing expression ability. It is the basic capabilities that colleges and universities need for the society and the enterprise. In the experiential teaching, the teaching requirements for improving the students' comprehensive qualities can be fully reflected and exercised in teaching activities, and can achieve higher classroom effects and teaching satisfaction.
\end{abstract}

\section{Introduction}

Experiential teaching needs to design certain teaching situations in the teaching process. It is a teaching strategy and method for students to experience or experience the teaching process, and to understand knowledge and enhance innovation ability through teaching experience. The experiential teaching process pays more attention to the interaction between teaching and learning, the interaction between teachers and students, the interaction between students and society, and the importance of students' participation and initiative in the teaching process. Experiential teaching attaches importance to the increase in the proportion of experiential and practical teaching and natural integration, allowing students to experience the theory through more experience and experience, and apply it to practice and guide the cycle of practice. How to cultivate innovative entrepreneurial talents in colleges and universities is particularly important, but from the current status of China's colleges and universities innovative entrepreneurial talent training, there are mainly single talent training standards, innovative talents and entrepreneurial talent training is relatively independent, both related Degrees and systems are not strong and many other issues[1].

\section{The Basis and Significance of Experiential Entrepreneurship Education}

\subsection{The Theoretical Basis of Experiential Entrepreneurship Education.}

Experiential entrepreneurship education model is designed based on the effectiveness of emotions in cognitive activities. It gives us new inspiration to solve the current problem of lack of motivation for students in entrepreneurship education. Emotional regulation refers to the organization or disorganization of emotions to cognitive activities [2], that is, moderate intensity and pleasant emotions are conducive to the organization and conduct of intelligence operations. Excessive and weak emotions and poor emotions may lead to thinking. Confusion and memory difficulties [3]. Therefore, experiential teaching is to arouse students' active and healthy emotional experience during the teaching process, directly improve the students' enthusiasm for learning, and make learning activities become students' initiative and happy things[4]. 


\subsection{The Positive Significance of Experiential Entrepreneurship Education.}

Traditional non-experienced entrepreneurship education is easy for students to become inert. Students' learning is mainly for examinations and credits, and the knowledge they possess cannot be applied to practice. Experiential entrepreneurship education emphasizes that individual knowledge is derived from sensory experience. Through the system's scenario design, learners can perform immersive experience learning. Maximize the initiative of college students to learn independently and promote them to "doing high school [5]."

\section{Experiential Teaching Process Design}

\subsection{Team Design of School.}

To build an effective learning team, teams must be meticulously designed, starting from the number of teams, competencies, gender ratios, assessment methods, team performance evaluation systems, etc., to minimize the "big pot meal" and "free rider behavior". Make personal capabilities and teamwork get the most out of you [6]. The experiential teaching process of innovation and entrepreneurship courses is mainly based on the participation of the team. Therefore, the first choice for experiential teaching is to establish a student team. In order to enhance the initiative and enthusiasm of team members to participate in and avoid the situation of partial student replenishment, the number of student teams is not easy to be excessive, generally 4-6 people are preferred. The methods of team design include free grouping, random grouping, and grouping according to student number order. Random groupings can be carried out in the form of warm field activities, or combined in the form of random number selection.

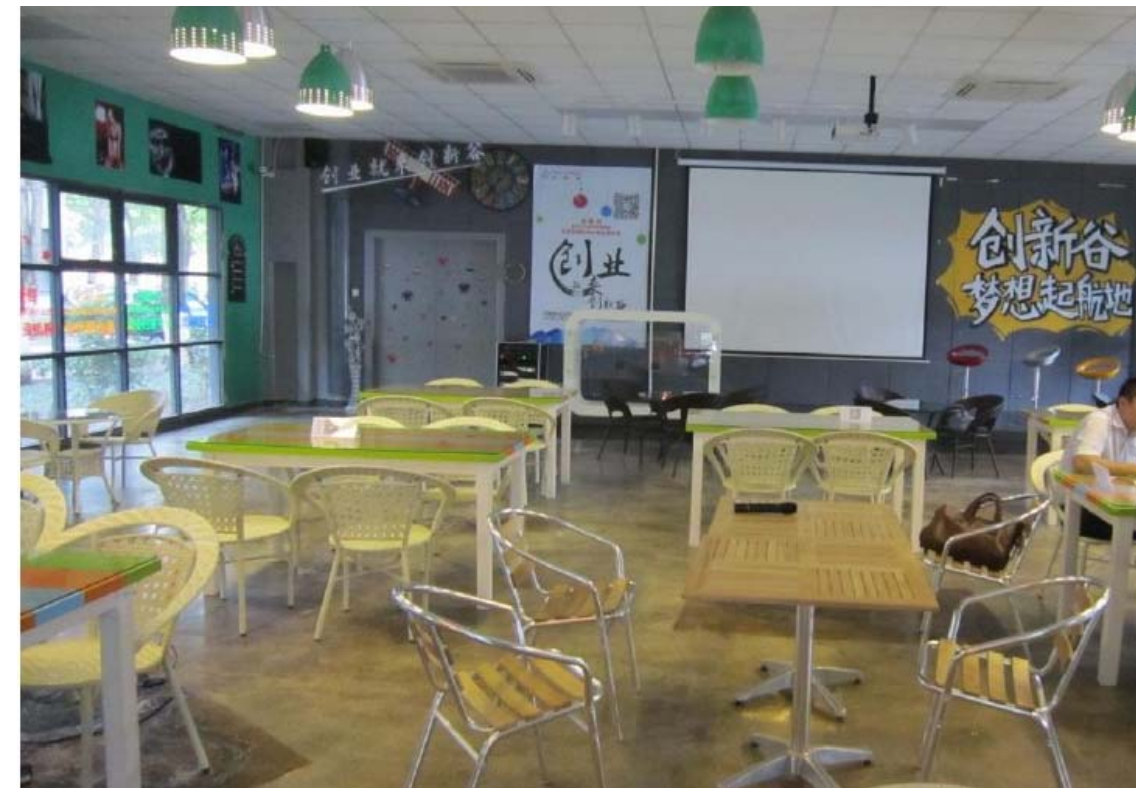

Fig 1. Experiential teaching grouping construction mode

Take the team design of a class taught by the author as an example. In order to strengthen communication and cooperation among students, students in this class are encouraged to use the dormitory as a unit to form a team when they are free to group. Students will be enrolled at the beginning of the semester. The sequence is divided into 16 groups, of which the first 15 groups are 4 and the last group is 5. In the teaching process, group activities are mainly carried out in this group, and the end-of-term operations are also based on this team. During the course of the course, according to the specific content of the selected teaching practice activities team design, such as the Tokyo Tower game requires 10 people and the same ratio of men and women, so before the launch of the event allows students to freely set up teams. Whereas some activities require students to be divided into smaller groups (Groups 3-6), students are randomly grouped according to interesting activities. 


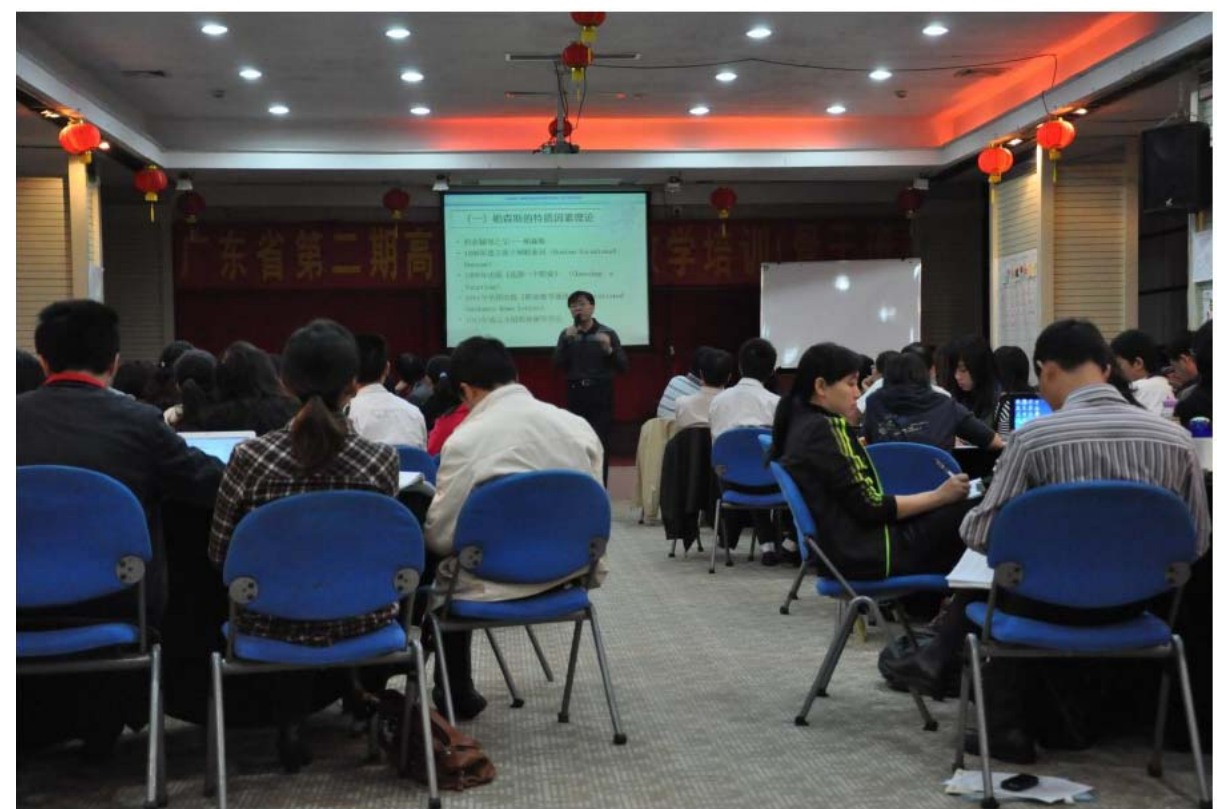

Fig 2. Experiential Entrepreneurship Education Grouping Process Control

\subsection{Activity Hosting.}

Innovative creative courses, like the other courses, are also responsible for cultivating students' comprehensive abilities while delivering content. There are mainly three forms of activity hosting: teacher presiding, student representative presiding, teacher and student representative co-hosting. The activities organized by student representatives and teachers and student representatives can cultivate and train students' organizational skills. Teacher-hosted activities can also play an exemplary role in cultivating organizational skills for students [7].

\subsection{Active Process Control.}

The activity time of this course is generally controlled within two classes. Therefore, in the process of organizing the event, the time control must be done first. Each link of the activity should be designed in advance and strictly controlled during the course of the activity so as to be successfully completed. Activity. Before the activity is carried out, preparations should be made in advance to facilitate the smooth progress of the activities. In the process, guidance and guidance work should also be done so that activities can be carried out according to the requirements of the activities and the purpose of the activities. The final part of the process should allow students to sum up the knowledge of the corresponding chapters in order to exercise students' ability to refine and summarize. At the same time, students also learn more in-depth knowledge and skills. For example, when talking about the chapter of the innovation process, design a "flying egg" practice. The activity requires that the egg be an "aircraft" that can make the egg "fly" farthest and the egg in flight is not broken. The raw materials required for this activity are available: 1 raw egg, 2 paper cups, 4 chopsticks, 2 balloons, 1 plastic bag, several tapes, several ropes, several newspapers, a pair of scissors, and a bottle of glue. The time is practical: 20 minutes for event introduction and preparation, 30 minutes for innovative works, 30 minutes for each group, and 20 minutes for teachers. In the course of the activity, it is designed strictly in accordance with the above time, and guides the students how to overcome the difficulties in completing the work based on knowledge accumulation and guide the students in an orderly presentation of the work. After the demonstration of each group's work is completed, the experience sharing and process summary of the team work design are carried out. Finally, the teacher combines and decomposes and summarizes the activities in several stages of the innovation activities, and integrates the theoretical knowledge into the activities. 


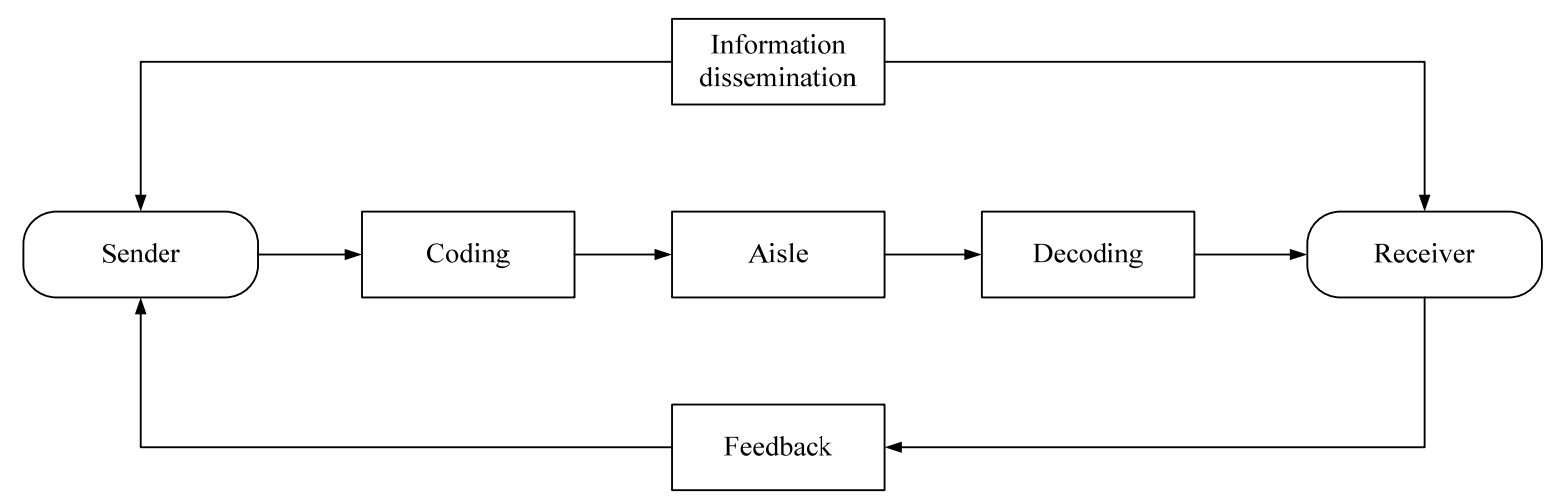

Fig 3. Experiential Entrepreneurship Education Feedback Process

\subsection{The Process Design of the Final Works.}

The end-of-period assignment of a creative curriculum in a class is based on teamwork and produces an innovative work based on team communication and cooperation. The completion of the final period works is divided into three stages. The first stage is the stage of the final stage of the work: the form and requirements of the final stage assignments are assigned to each team at the beginning of the semester; the second stage is the open stage report stage: during the semester, each group is asked to open a topic Reporting; The third phase is the submission phase of the final project: At this stage, the work of each group is completed and submitted and accepted, and a summary report of the production is made. Through this process, the final works will be procedure integrated so that students can actively think about how to achieve an innovative work and apply the theory to practice in the process of learning.

\section{Practical Applications of Experiential Entrepreneurship Education}

\subsection{Experiential Teaching in the Classroom.}

1) Case teaching. In case teaching in entrepreneurship education, before designing classroom teaching, teachers should combine the students' current learning situation to determine the topic and consider whether the selected case is appropriate. In specific case teaching, teaching objectives should be selected according to the case, including the setting of knowledge goals and capability goals, and key and difficult points should be drawn to guide instructional design ideas. In the course of case teaching, teachers can collect information on China's employment situation, employment policies, etc. Students can collect specific examples of job talents and successful entrepreneurs. Filter these data into a theme and apply it. After the case analysis is completed, it enters the interactive discussion session and completes the teaching summary.

2) Role playing. That is, the simulation platform is designed to allow students to participate in the recruitment, recruitment, and experience of entrepreneurship education. Teachers can divide the whole class into several large groups. Each group has a number of recruiters and a number of candidates. Re-determine recruitment topics, preset recruitment forms (set up resumes, interviews, written tests, case studies, on-site operations, and other necessary links), and then conduct on-site simulations, use multimedia to set up recruitment situations, and demonstrate.

\subsection{Practice outside the Classroom.}

1) Practical experience. Entrepreneurship education should step out of the classroom and be actively practiced. The first is to organize students to participate in off-campus internships, training base visits and research, so that students can truly feel and understand the company; second, invite professionals or entrepreneurs to come to the school to give lectures or guide students to carry out entrepreneurial practice; third is to use the internship In other ways, students are allowed to go into the company to practice and communicate directly with the company's staff. 
2) Development training. Teachers can design some ideological and challenging games and expand students' training so as to effectively cultivate students' active and enterprising learning, working attitude and cooperation consciousness. In addition to designing classroom activities in the classroom, teachers should also actively design some outdoor outreach activities so as to stimulate students' potential, temper their will, inspire students' imagination and creativity, and cultivate students' interpersonal communication skills and team cooperation skills.

3) Entrepreneurial simulation. The core of the entrepreneurial simulation approach is to develop a business plan. Entrepreneurial planning is a strategic blueprint, which mainly embodies the concept of new enterprises, including the allocation and utilization of human resources, material resources, and social resources. In the process of drawing up a business plan, students can use their free groupings to propose their own entrepreneurial ideas and ideas based on their hobbies and interests. Finally, they can integrate within the group and comprehensively design the group's business plan.

\subsection{Restructure the Curriculum System Integrate All-Round Quality Education into the Entire Teaching Process.}

Constructing a scientific and rational curriculum system is the key to achieving the goal of cultivating innovative and entrepreneurial talents. The foundation of the curriculum system is the goal of talent training, namely, the knowledge goal, ability goal and quality goal; the construction of the curriculum system is characterized by the innovation and entrepreneurship education throughout the entire career education. This article takes the chain enterprise management and management as an example. Explain the construction of innovation and entrepreneurial talents training mode. Through the first academic year of study and training. Achieve smooth "entry" for students; study and training for the second academic year to achieve effective "people"; third year of study and practice to achieve student success "personnel." After three academic years of study and training. Achieve progressive improvement in students' professional entrepreneurial abilities and qualities.

\subsection{Actively Explore the Reform and Practice of Teaching Models.}

Effectively promote the application of simulated simulation teaching and task-driven teaching, and improve students' actual combat ability in innovation and entrepreneurship. Simulation teaching method is a kind of teaching method that aims to achieve the purpose of combining theory with practice by simulating the actual work procedures and links. By creating chain enterprise management jobs, creating a real chain enterprise management operating environment. Enhance student job adaptability. For example, the simulation teaching method is used in the teaching of chain store operation management practice. Divide a class of students into learning groups. Each learning group will set up a simulation company to simulate the establishment of a simulation company (company name, location of stores, preparation of "Articles of Association", capital verification report, company registration, business license acquisition, etc.) The basic process of simulating the company's operations (procurement, product pricing, product distribution, advertising promotion, human resources management, income distribution, etc.) and operational performance evaluation tasks. The results of the work are presented in the form of working papers, market research reports, financial statement reports, company promotion plans, employee recruitment plans, employee incentive policies, and other documents. The operation of the simulation company is completed on the basis of internal cooperation, external effective competition, and continuous innovation. It is conducive to the development of students' internal potential, fosters the team spirit of the students, improves the students' ability to resist setbacks, and accumulates for employment and entrepreneurship. Valuable experience. The task-driven teaching method is to enable students to carry out teaching activities under the drive of typical work tasks, and guide students to complete a series of tasks from simple to complex and from easy to difficult. This leads to a clear line of thought, method, and knowledge. In the process of completing the task, develop the ability to analyze problems and solve problems. The use of task-driven teaching method is conducive to the development of the team spirit of the students. The main reasons are: First, the work tasks of the chain companies are relatively large, and it is difficult for students to personally complete them. Only by 
relying on the strength of the team to complete the task; second, the class usually complete the task by grouping, within the group there is a division of labor and cooperation, the competition between the groups, so as to stimulate students' interest, foster innovation, collaborative awareness and team spirit. It will be helpful to improve students' management skills.

\subsection{The Conditions for the Implementation of the Training Mode.}

Innovative and entrepreneurial talents the implementation of innovative entrepreneurial talents training model. Needs to cooperate in school-enterprise cooperation, educate people, collaborate on employment, and develop cooperatively on the basis of two courses, sports, English office automation, enterprise establishment process management foundation, accounting basis chain business basic market research and forecast, small cycle chain enterprise job training Chain Store Commodity Purchasing Management Chain Logistics Distribution Management Practice Chain Enterprise Marketing, Art Elective Promotion Techniques and Business Negotiation Commodity Management Practice, Human Resource Management Chain Store Management, Simulation Training Large-scale Chain Company Job Training Customer Relationship Management, Frustration Training Chain Stores Development and design of social etiquette, economic writing, economic law, practical business planning and design, employment guidance and other production internships, and the practice of entrepreneurship inside and outside schools have been realized.

\section{Conclusion}

The entrepreneurship education for college students is an important means for cultivating innovative talents and is an important task for the construction of an innovative country. Its significance is profound. The traditional non-experienced entrepreneurial education suppresses the entrepreneurial passion of college students, constrains the creative abilities of college students, and does not cultivate true entrepreneurial talents. Only the reform of entrepreneurship education and the use of multilevel and multistage experiential teaching can really stimulate the entrepreneurial passion of college students and mobilize the entrepreneurial initiative. The situation of "mass entrepreneurship and innovation" can really be realized.

\section{References}

[1]. Liu Shayna, et al. Research on Experiential Teaching Model. Education Theory and Practice, Vol. 6 (2015) No.16, p.57-60.

[2]. Goo Shipping, Ding Banteng, et al. Exploration of Experiencing Teaching Model in College Entrepreneurial Education Curriculum. College Education, Vol. 7 (2016) No. 34, p.150-155.

[3]. Zeng Shu, ET al. Encourage entrepreneurship education to promote the cultivation of innovative talents. China Education New, Vol. 10 (2008) No. 32, p.63-69.;

[4]. Yang Zigong, et al. "Task-driven" teaching method in the mold manufacturing integrated training. Meld manufacturing, Vol. 12 (2011) No.26, p.411-416.

[5]. Zhang Yuri, et al. Research and practice of entrepreneurship education in China in the era of innovation, Modern Education Press, Vol. 5 (2006) No. 36, p.321-329.

[6]. Li Zheng, ET al. Internal mechanism and development strategy. Social Sciences Academic Press, Vol. 4 (2010) No. 15, p.127-131.

[7]. Zhang Yuri, ET al. the status quo and future prospects of entrepreneurship education in the world. Research on entrepreneurial management, Vol. 2 (2009) No. 23, p.37-43. 